\title{
REMIX TECHNICS WITH EXE LEARNING TO IMPROVE STATISTICS LEARNING USING MOODLE
}

\author{
Gerardo Heckmann \\ Universidad Nacional de Córdoba, Argentina \\ heckmann@eco.unc.edu.ar
}

\section{A CHALLENGE IN STATISTICS EDUCATION IN THE AGE OF SOCIAL NETWORKING AND DISTANCE EDUCATION}

If there is an issue that is particularly hard to understand for students in statistical inference that is the concept of the distribution of a combination of random variables: an estimator.

In a massive, 300 or more students' classroom, the challenge is even greater. This situation is common at the Faculty of Economics of the National University of Córdoba (FCEUNC), Argentina, with more than 12,000 students.

The purpose of this work is to show how to take advantage from the production of Scorm materials that facilitate the integration of resources available on the web to improve the study of statistical issues in mass classrooms through the interaction with Moodle platform.

Based on Exe Learning, an SCORM was developed. This is an interactive material to complement the study of Sampling Distributions. Includes sections designed to ensure understanding of the concepts, based on the use of simulators from the Rice University and auto evaluation questions. You may visit the site at: http://aulas.eco.unc.edu.ar/course/view.php?id=7

Implemented in a course of statistical inference at FCE-UNC it seems to be a very good alternative in the search for high degree of personalization in the interaction with the students, despite the massiveness of the number of attendees. A personal score is assigned on the base of the student interaction with the Scorm and registered in Moodle. Feedback is automatically generated while using the app (correct answers are stimulated with Genial! Well done!, etc. and those wrong with clues to get to the correct answer and an expression of encouragement: Try again!

It is important to remark that this kind of materials also seem to be an excellent tool to motivate teachers (materials production) and students (Statistics education in the age of social networking and distance education). Also are intended to close the gap in advancing Statistical education using technology and mobile devices. 